\title{
Providing Medical Information to Older Adults in a Web-Based Environment: Systematic Review
}

Bianca McLean ${ }^{1}$; Nazia Hossain², MD; Valentina Donison ${ }^{3}$, BSc, MN; Mikaela Gray ${ }^{4}$, MI; Sara Durbano ${ }^{5}$, MSc, RKin; Kristen Haase ${ }^{6}$, BSc, MA, PhD, RN; Shabbir Muhammad Husayn Alibhai ${ }^{7}$, MSc, MD; Martine Puts ${ }^{3}$, PhD, $\mathrm{RN}$

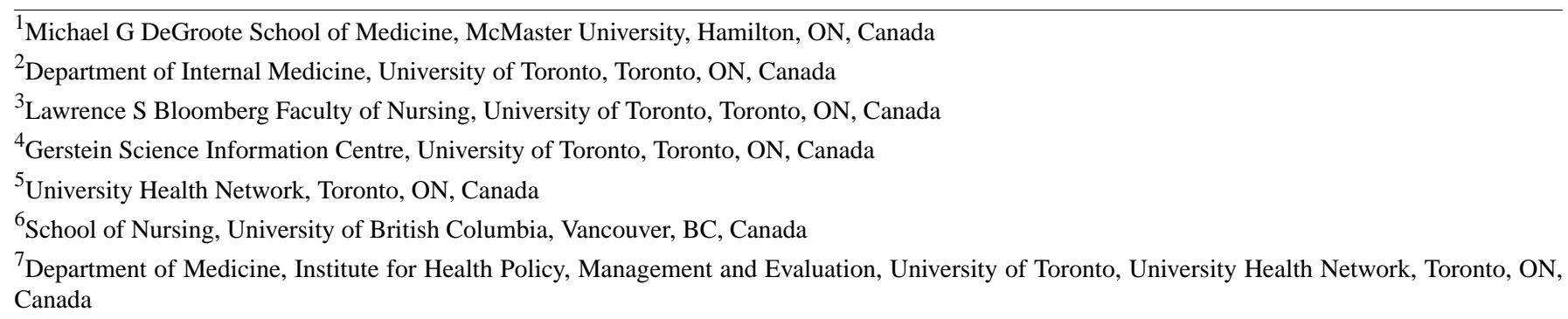

Corresponding Author:

Martine Puts, PhD, RN

Lawrence S Bloomberg Faculty of Nursing

University of Toronto

155 College Street Suite 130

Toronto, ON

Canada

Phone: 14169786059

Email: martine.puts@utoronto.ca

\begin{abstract}
Background: Cancer is a disease that predominantly affects older adults, and several organizations recommend the completion of a geriatric assessment to help with cancer treatment decision-making. Owing to a shortage of geriatric teams and the vast number of older adults diagnosed with cancer each year, a web-based geriatric assessment may improve access to geriatric assessment for older adults. We systematically reviewed the literature to obtain the latest evidence for the design of our web-based geriatric assessment tool Comprehensive Health Assessment for My Plan.

Objective: This review aimed to probe the following questions: what is the impact of providing health test results to older adults in a web-based environment without the presence of a health care provider for patient-centered outcomes, including satisfaction, perceived harm, empowerment, quality of life, and health care use (eg, hospitalization, physician visits, emergency room visits, and costs), and what recommendations do older adults and developers have for designing future apps or websites for older adults?

Methods: This systematic review was guided by the PRISMA (Preferred Reporting Items for Systematic Reviews and Meta-analysis) statement. Studies were limited to publications in English that examined a web-based tool that provided test results to older adults (aged $\geq 65$ years) without the presence of a health care provider. A health sciences librarian performed the search on November 29, 2019, on the following electronic databases: MEDLINE, Embase, CINAHL, PsycINFO, and the Cochrane Library. The quality of the included studies was assessed using the Mixed Methods Appraisal Tool Version 2018. The findings are summarized narratively and in tabular format.

Results: A total of 26,898 titles and abstracts were screened by 2 independent reviewers, of which 94 studies were selected for a full-text review, and 9 studies were included in this review. There were only 2 randomized controlled trials of high quality that explored the effects of receiving health care results on the web via eHealth tools for older adults or provided evidence-based recommendations for designing such tools. Older adults were generally satisfied with receiving screening results via eHealth tools, and several studies suggested that receiving health screening results electronically improved participants' quality of life. However, user interfaces that were not designed with older adults in mind and older adults' lack of confidence in navigating eHealth tools proved challenging to eHealth uptake and use. All 9 studies included in this systematic review made recommendations on how to design eHealth tools that are intuitive and useful for older adults.
\end{abstract}


Conclusions: eHealth tools should incorporate specific elements to ensure usability for older adults. However, more research is required to fully elucidate the impact of receiving screening and results via eHealth tools without the presence of a health care provider for patient-centered outcomes in this target population.

(JMIR Aging 2021;4(1):e24092) doi: 10.2196/24092

\section{KEYWORDS}

eHealth; systematic review; geriatric assessment; geriatric oncology

\section{Introduction}

\section{Background}

For older adults with cancer, several organizations recommend the completion of a geriatric assessment to help with cancer treatment decision-making [1,2]. A geriatric assessment consists of several questionnaires and tests that assess the medical, social, and psychological functioning of older adults to determine what interventions could be implemented to optimize their health and well-being [3]. However, owing to the shortage of geriatric teams and the large number of older adults diagnosed with cancer each year, access to a geriatric assessment remains to be limited. A web-based geriatric assessment may improve access for older adults. Although a few web-based geriatric assessment tools have been developed [4-6], these tools do not provide older adults with their test results without a health care provider being present. In addition, these tools would not increase access to a geriatric assessment because they still require the input of health care professionals, who are currently in low supply and high demand. Our overarching aim is to review the literature to develop a web-based geriatric assessment, the Comprehensive Health Assessment for My Plan (CHAMP), which will provide test results directly to older adults and help triage patients who are in greater need of geriatric consultation. To best design the CHAMP tool, we were interested in understanding the impact of receiving health test results in a web-based environment without the presence of a health care provider on older adults. We were also interested in consolidating the recommendations made by older adults and website developers for designing web-based tools for older adults. Therefore, we systematically reviewed the literature to obtain the latest evidence to inform the future design of our CHAMP tool.

As older adults with multiple comorbidities make up an increasing proportion of the population, there is a growing focus on equipping these patients with the tools needed to manage their own health. The aim is to provide patients with a sense of control over their medical conditions and decrease health care utilization [7]. Older patients particularly value the ability to manage their health independently at home, and minimizing reliance on health care resources, such as emergency rooms and inpatient units, is therefore an important outcome measure [8-10]. One strategy to meet these needs is the development of web-based health management tools that can be linked to patients' eHealth records and accessed from personal devices (such as smartphones, tablets, and laptops). A wide variety of eHealth tools have been developed [5-7,11]). For example, some enable patients to view results of laboratory and imaging tests [11], whereas others provide customized health care advice or allow patients to communicate directly with members of their health care team [12]. Web-based tools have also been developed for the management of specific medical conditions such as cardiovascular disease [13] and diabetes [14]. The adoption of these resources was found to improve patient outcomes in these studies. In a small study of 169 computer users aged 50 years and older, Zettel-Wattson and Tsukerman [15] discovered that $90 \%$ of participants found patient portals helpful for managing their health and $80 \%$ felt that portals gave them control over their health. A systematic review by Ferreira et al [16] showed that providing patients access to their electronic medical records improved patient understanding of their disease and helped break down barriers in the physician-patient relationship.

Despite the number of eHealth tools and their potential to enhance patient care, barriers exist to widespread adoption, especially among patients older than 65 years. Previous studies have cited concerns about privacy and security, lack of access to technology, low computer literacy, high computer anxiety, complex user interfaces, and concerns about losing face time with health care providers as key factors that prevent older adults from routinely using eHealth management systems [7,17-20]. Disparities in uptake have also been found based on age group, ethnicity, education level, and physical and cognitive abilities $[7,18,21]$.

Studies have varied in their conclusions about optimal eHealth tool design, and few have offered specific recommendations to address these barriers. Some authors suggest that complete medical records, medication lists, test results, and condition-specific health advice are consistently appreciated by patients accessing web-based portals [15,17,22]. Khan et al [23] studied perceptions of a medication management system and found that participants enjoy visual representations of data but would also like accompanying text descriptions to fully understand their meaning. Furthermore, some patients desire the ability to receive appointment reminders, refill medications, or communicate with health care professionals through secure messaging. However, the impact of various designs on patient-centered outcomes remains to be fully explored [24].

\section{Objectives}

To best design the CHAMP tool to deliver geriatric assessment results to older adults with cancer, our review questions were as follows:

1. What is the impact of websites and apps providing health test results to older adults in a web-based environment without the presence of a health care provider for patient-centered outcomes such as satisfaction, empowerment, quality of life, and health care use (eg, 
hospitalization, physician visits, emergency room visits, and costs)?

2. What recommendations do older adults and developers have for designing future apps or websites for older adults?

We were most interested in understanding the impact of receiving health care screening and test results in the electronic environment on patient-centered outcomes such as satisfaction, empowerment, and quality of life compared with cancer-specific outcomes such as progression-free survival because we expect that the results of this literature review will be applicable to the care of older adults in many other fields of medicine, not just oncology. Furthermore, in geriatric oncology, factors other than progression-free survival and other cancer-specific outcomes are of substantial importance. Quality of life, overall functioning, and health care use have become increasingly important from the patient's viewpoint. Hence, it is both of service to the patients that we care for, and to other providers of care for older adults to understand the impact of receiving health results in a web-based environment from the patient perspective $[25,26]$.

\section{Methods}

\section{Review Methodology}

We used systematic review methodology according to the Cochrane Handbook [27] and guided by the Preferred Reporting Items for Systematic Reviews and Meta-analyses (PRISMA) statement [28].

\section{Search Methods}

Database searches were conducted by a health sciences librarian (MG) in Ovid MEDLINE, Ovid Embase, EBSCO CINAHL Plus with Full Text, Ovid PsycINFO, and the Cochrane Library using the Wiley interface. A combination of database-specific subject headings and text word searches was used to search for concepts included in our population intervention comparator outcomes search with publication date limits applied to identify articles published in the last 10 years. Keywords included "telehealth," "eHealth" or "mHealth" or "mobile health" or "digital health" or "telecommunications" or "electronic mail" or "cell phone" or "smartphone" or "Internet" or "Mobile Applications," "older adults," and "aged." Although a geriatric assessment is not the same as a patient portal (the former is a health assessment, whereas the latter is a web-based shared medical record), we expanded the search to include portals to identify any studies that looked at the impact of providing test results web-based on older adults' health outcomes. The results of this search were imported with other search results. Published filters were applied to limit the publication type to randomized controlled trials (RCTs) [29-32]. See Multimedia Appendix 1 for the MEDLINE search. The searches were run on November 29, 2019, and the search period was from January 1, 2009, to November 29, 2019. The search period was limited to 2009 onward to ensure that any apps and website or design recommendations would still be relevant as eHealth is a rapidly developing field. Publications in English were eligible for inclusion. Reference lists of included studies were reviewed to identify any additional relevant studies.

Papers were included if the following criteria were met:

- Included a population of older adults (aged above 65 years or the mean or median age in the study population was above 65 years, or if younger, subgroup analysis of those above 65 years was reported)

- Included an intervention in which older adults received results of health screening or tests completed in a web-based environment or eHealth (not including live chats with nurses, therapists, or doctors to go over test results)

- Compared the intervention to receiving the results of tests or screening in person from a health care provider or had no control group

- Focused on the following intervention outcomes: (1) patient-centered outcomes such as satisfaction, perceived harm, anxiety, depression, distress, empowerment, and quality of life; (2) health care use (eg, hospitalization, physician visits, emergency room visits, and costs); and (3) patient understanding of instructions of the tool used or provided recommendations on how to design eHealth tools for older adults

\section{Study Selection}

We included studies through a two-step process (see Figure 1 for our PRISMA flowchart). First, abstracts and titles were screened by two independent reviewers. Then, all potentially relevant full-text articles were reviewed for study inclusion by two independent reviewers. We used the Covidence software [33] to facilitate the study selection process. In case of disagreements, a third reviewer reviewed the abstract or full text, and a consensus decision was made whether to include or exclude the study. 
Figure 1. PRISMA (Preferred Reporting Items for Systematic Reviews and Meta-analyses) flowchart for study selection.
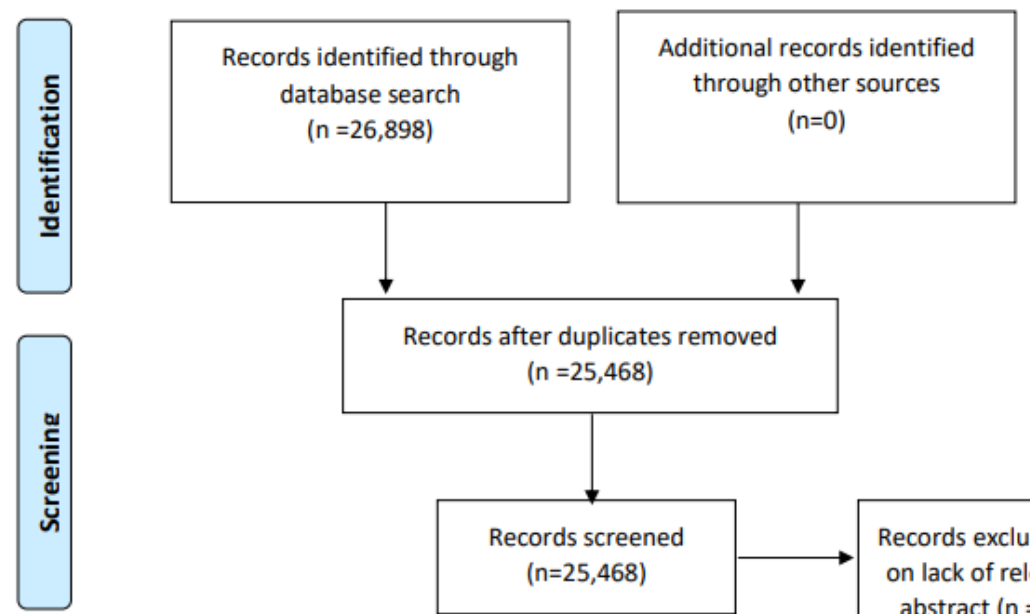

$(n=25,468)$
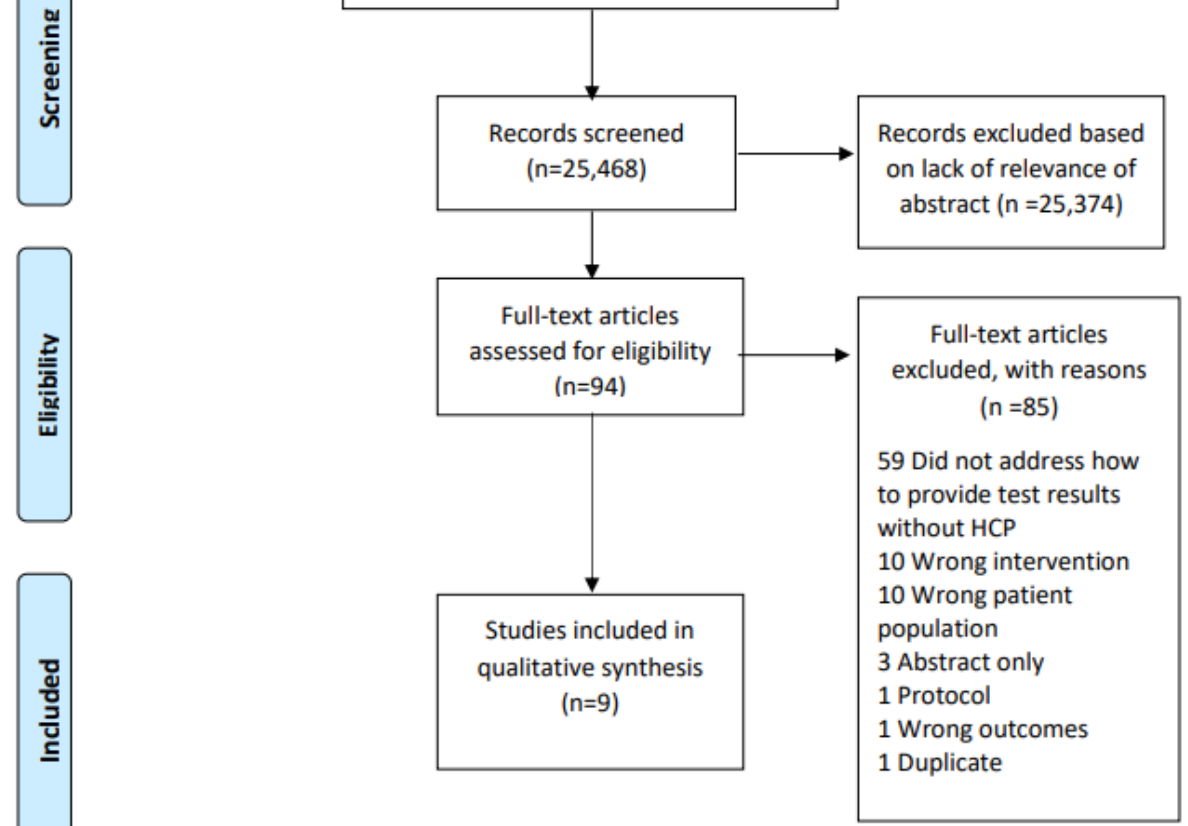

\section{Data Abstraction}

We used standardized data collection forms developed by the research team using Excel. Data were abstracted by two reviewers independently and compared. The information that was abstracted included characteristics of the study population, study design details, details of the intervention (app or website), the methodology used to develop the app or website, details on the app or website, the impact of receiving web-based results for patients (on the aforementioned patient-centered outcomes), and details on the analyses used. For papers referring to a published study protocol, we obtained the study protocol paper to obtain the full methodological details of the study. After data abstraction, we had the missing information from all 9 studies. We contacted the authors of all the studies via email to inquire about missing information, and authors of 4 studies responded. As the studies were heterogeneous in design, intervention delivered, and outcome measures used, we summarized the abstracted data qualitatively because a meta-analysis was not possible.

\section{Quality Assessment}

We assessed the quality of the included studies using the Mixed Methods Appraisal Tool (MMAT) version 2018 [34-36]. MMAT is a quality assessment instrument that is useful for assessing qualitative, quantitative, and mixed methods studies. We noticed that several studies included a qualitative component (eg, multimethods and mixed methods studies); therefore, we chose to use MMAT over Cochrane Risk of Bias tool, which is not able to review these qualitative components. We used MMAT to review study quality, but we did not exclude any study based on the score as our aim was to understand all the evidence that was available and use that for our development of a web-based geriatric assessment.

\section{Data Analysis}

We summarized the results using a narrative descriptive synthesizing approach. A pooled analysis was not conducted because of heterogeneity in study inclusion criteria, interventions, and outcomes.

\section{Results}

\section{Description of Included Studies}

Of the 9 studies included in this review, 4 were qualitative studies [37-40], 2 were RCTs [41,42], 2 were mixed methods studies $[43,44]$, and 1 was a quasi-experimental controlled study [45]. Overall, 8 studies were conducted in the United States [37-42,44,45], whereas 1 was a multinational study conducted in Western Europe [43]. All 9 studies included in this systematic review were published between 2015 and 2019. The sample size of the studies ranged considerably, with qualitative studies ranging from 24 to 44 participants [37-40] and the RCTs ranging from 50 to 272 participants [41-43]. The mixed methods study 
ranged from 88 ( 47 for the focus group and 41 for the pilot trial) [43] to 123 participants (23 for the focus group and 100 for the phone survey) [44], whereas the quasi-experimental study had 200 participants [45]. In addition, 4 studies evaluated the attitudes and experiences of older adults with patient portals [38,39,44,45], 2 studies tested web-based apps developed to deliver condition-specific (eg, cancer, cardiovascular disease) interventions [37,43], 1 study tested a user interface for a home health website [40], 1 tested a web-based decision aid [42], and 1 tested a theory-based patient portal training program [41]. A summary of the characteristics of each study included in this systematic review is shown in Table 1.

Table 1. Description of the included studies.

\begin{tabular}{|c|c|c|c|c|c|c|c|c|}
\hline $\begin{array}{l}\text { Study (refer- } \\
\text { ence) }\end{array}$ & Study design & Location & $\begin{array}{l}\text { Sample size; } \\
\text { population }\end{array}$ & $\begin{array}{l}\text { Average age } \\
\text { (years) }\end{array}$ & Female $(\%)$ & Sampling & $\begin{array}{l}\text { Intervention } \\
\text { app or tool }\end{array}$ & Analysis \\
\hline $\begin{array}{l}\text { Alpert et al } \\
(2016) \text { [39] }\end{array}$ & Qualitative & $\begin{array}{l}\text { United } \\
\text { States }\end{array}$ & $\begin{array}{l}31 \text { patient inter- } \\
\text { views; } 2 \text { focus } \\
\text { groups of } 13 \\
\text { health care pro- } \\
\text { fessionals }\end{array}$ & $\begin{array}{l}\text { Not reported } \\
\text { (range 18- } \\
79 \text { ) }\end{array}$ & 58 & Convenience & $\begin{array}{l}\text { My preventa- } \\
\text { tive care patient } \\
\text { portal }\end{array}$ & $\begin{array}{l}\text { Critical incident } \\
\text { technique }\end{array}$ \\
\hline $\begin{array}{l}\text { Irizarry et al } \\
(2017)[44]\end{array}$ & Mixed methods & $\begin{array}{l}\text { United } \\
\text { States }\end{array}$ & $\begin{array}{l}100 \text { older adults } \\
\text { in phone sur- } \\
\text { vey, } 23 \text { in focus } \\
\text { group }\end{array}$ & $\begin{array}{l}\text { Focus group: } \\
73 \text {; phone } \\
\text { survey: } 77\end{array}$ & $\begin{array}{l}\text { Focus group: } \\
52.2 \% \\
\text { phone sur- } \\
\text { vey: } 46.2 \%\end{array}$ & Convenience & Patient portal & $\begin{array}{l}\text { Thematic analy- } \\
\text { sis, Kruskal } \\
\text { Wallis rank test, } \\
\text { chi-square test }\end{array}$ \\
\hline $\begin{array}{l}\text { Loh et al } \\
(2018) \text { [37] }\end{array}$ & Qualitative & $\begin{array}{l}\text { United } \\
\text { States }\end{array}$ & $\begin{array}{l}18 \text { older adults } \\
\text { with malignan- } \\
\text { cy; } 13 \text { care- } \\
\text { givers }\end{array}$ & $\begin{array}{l}\text { Patient: } 77 ; \\
\text { caregiver: } 70\end{array}$ & $\begin{array}{l}\text { Patient: } 17 ; \\
\text { caregiver: } 92\end{array}$ & Convenience & $\begin{array}{l}\text { TouchStream } \\
\text { app to deliver } \\
\text { geriatric oncolo- } \\
\text { gy interventions }\end{array}$ & $\begin{array}{l}\text { Conventional } \\
\text { content analysis }\end{array}$ \\
\hline $\begin{array}{l}\text { Nahm et al } \\
(2019)[41]\end{array}$ & $\mathrm{RCT}$ & $\begin{array}{l}\text { United } \\
\text { States }\end{array}$ & $\begin{array}{l}272 \text { older adults } \\
\text { with chronic } \\
\text { disease }\end{array}$ & 70 & 70.2 & Convenience & $\begin{array}{l}\text { Theory-based } \\
\text { patient portal e- } \\
\text { learning pro- } \\
\text { gram }\end{array}$ & $\begin{array}{l}\text { Linear mixed } \\
\text { model, } t \text { test, } \\
\text { chi-square test }\end{array}$ \\
\hline $\begin{array}{l}\text { Portz et al } \\
(2019) \text { [38] }\end{array}$ & Qualitative & $\begin{array}{l}\text { United } \\
\text { States }\end{array}$ & $\begin{array}{l}24 \text { older adults } \\
\text { with chronic } \\
\text { disease }\end{array}$ & 78 & 71 & Stratified & $\begin{array}{l}\text { Kaiser perma- } \\
\text { nente col- } \\
\text { orado's patient } \\
\text { portal-my } \\
\text { health manager }\end{array}$ & $\begin{array}{l}\text { Theoretical } \\
\text { analysis based } \\
\text { on the technolo- } \\
\text { gy acceptance } \\
\text { model }\end{array}$ \\
\hline $\begin{array}{l}\text { Smallwood et } \\
\text { al (2017) [42] }\end{array}$ & Pilot RCT & $\begin{array}{l}\text { United } \\
\text { States }\end{array}$ & $\begin{array}{l}50 \text { older women } \\
\text { with } \mathrm{BMD}^{\mathrm{c}} \text { indi- } \\
\text { cating osteope- } \\
\text { nia or osteoporo- } \\
\text { sis }\end{array}$ & $\begin{array}{l}\text { Median } 79 \\
\text { years; mean } \\
\text { not reported }\end{array}$ & 100 & Stratified & $\begin{array}{l}\text { Decision aid } \\
\text { within patient } \\
\text { portal for osteo- } \\
\text { porosis }\end{array}$ & $\begin{array}{l}\text { ANOVA, } t \text { test, } \\
\text { chi-square test }\end{array}$ \\
\hline $\begin{array}{l}\text { Toscos et al } \\
(2016)[45]\end{array}$ & $\begin{array}{l}\text { Quasi-experi- } \\
\text { mental con- } \\
\text { trolled }\end{array}$ & $\begin{array}{l}\text { United } \\
\text { States }\end{array}$ & $\begin{array}{l}200 \text { patients } \\
\text { with significant } \\
\text { CAD }^{d}\end{array}$ & $\begin{array}{l}\text { Average age } \\
\text { not reported; } \\
58 \% \text { older } \\
\text { than } 66 \\
\text { years }\end{array}$ & 27.5 & Not reported & $\begin{array}{l}\text { Personal health } \\
\text { record }\end{array}$ & $\begin{array}{l}\text { Linear regres- } \\
\text { sion, } t \text { test, } \\
\text { Cochran-Man- } \\
\text { tel-Haenszel } \\
\text { test }\end{array}$ \\
\hline
\end{tabular}

${ }^{\mathrm{a}} \mathrm{RCT}$ : randomized controlled trial.

${ }^{\mathrm{b}} \mathrm{CVD}$ : cardiovascular disease.

${ }^{\mathrm{c}} \mathrm{BMD}$ : bone mineral density.

${ }^{\mathrm{d}} \mathrm{CAD}$ : coronary artery disease.

\section{Quality of Studies Included}

The application of MMAT to each study included in this review is shown in Multimedia Appendix 2. Overall, there were no studies of high quality that looked at the effect of web-based screening without the presence of a health care provider on older adults or evidence-based eHealth design. Most studies that were included had small sample sizes [42-44] and used convenience sampling [37,39-41,44], thereby increasing the risk of selection bias. We were unable to determine if the outcome assessors 
were blinded in all RCTs $[41,42]$, and we were unsure how randomization was performed in one of the RCTs [42]. In half of the qualitative studies included in this systematic review, we were unable to determine if there was coherence between the qualitative data source, analysis, and interpretation $[37,40]$.

The results of our systematic review are stated in the order of our aims. First, we review our findings on how receiving health screening in a web-based environment affects satisfaction, perceived harm, quality of life, and health care utilization by older adults. Second, we consolidate evidence-based recommendations on how to design eHealth tools that are useful and engaging for older adults.

\section{Objective 1: Effects of Health Screening in a Web-Based Environment}

A total of 7 studies in this review evaluated the effects of receiving health screening tests or results in a web-based environment without the presence of a health care provider on older adult participants' satisfaction $(n=6)$, perceived harm $(n=5)$, and quality of life $(n=5)[37-39,41,42,44,45]$. No studies included in this review reported on the effect of eHealth tools on health care use by older adults. The main findings of these studies are shown in Table 2. Screening results from eHealth tools were generally well received by older adults, but several studies suggested that older adults felt anxious about using new technology $[37,38,41,44]$. In total, $63 \%$ of patients in the study by Loh et al [37] found the TouchStream health app, used to deliver geriatric interventions to older adults with cancer, enjoyable to use. A total of 20 participants $(87 \%)$ in the study by Irizarry et al [44] felt that patient portals were generally useful. Five physicians (56\%) in the study by Alpert et al [39] suggested that the investigated patient portal improved patient empowerment. Participants in the study by Portz et al [38] indicated that the Kaiser Permanente patient portal improved patient-provider communication and saved patients time and money. Older women with osteoporosis felt more prepared to make treatment decisions after using the web-based decision-making tool designed and studied by Smallwood et al [42]. Most participants in the same study [42] were able to complete the web-based decision aid, although 5 participants (17\%) entered the information incorrectly. 
Table 2. Effects of receiving health information in web-based environment for older adults.

\begin{tabular}{|c|c|c|c|c|}
\hline Study & Satisfaction & Perceived harm & Quality of life & $\begin{array}{l}\text { Health care } \\
\text { use }\end{array}$ \\
\hline $\begin{array}{l}\text { Alpert et al } \\
\text { (2016) [39] }\end{array}$ & $\begin{array}{l}\text { Patients found the portal useful for instant- } \\
\text { ly accessing medical information. This } \\
\text { feature accounted for more than half of } \\
\text { the positive incidents recorded. Patients } \\
\text { appreciated receiving laboratory test }\end{array}$ & $\begin{array}{l}\text { A total of } 11 \% \text { of negative inci- } \\
\text { dents were because of patients } \\
\text { having difficulty interpreting labo- } \\
\text { ratory test results. Patients were } \\
\text { concerned when information was } \\
\text { incorrect or not updated. There } \\
\text { were more negative incidents } \\
(\mathrm{n}=82,72.6 \%) \text { than positive inci- } \\
\text { dents }(\mathrm{n}=31,27.4 \%)\end{array}$ & $\begin{array}{l}\text { Physicians }(\mathrm{n}=5,56 \%) \text { suggested } \\
\text { that the portal made patients feel } \\
\text { empowered }\end{array}$ & $N S^{\mathrm{a}}$ \\
\hline $\begin{array}{l}\text { Irizarry et al } \\
\text { (2017) [44] }\end{array}$ & $\begin{array}{l}\text { A total of } 87 \%(\mathrm{n}=20) \text { of participants } \\
\text { generally felt that the patient portal was } \\
\text { useful. Participants with both low and high } \\
\text { health literacy expressed interest in portal } \\
\text { training. Participants who had experienced } \\
\text { chronic illness praised the convenience of } \\
\text { web-based laboratory results }\end{array}$ & $\begin{array}{l}57 \% \text { of participants }(\mathrm{n}=13) \text { had } \\
\text { anxiety and frustrations about us- } \\
\text { ing technology because of their } \\
\text { perceived lack of technological } \\
\text { skills. This caused them to rely on } \\
\text { family members to use the patient } \\
\text { portal }\end{array}$ & NS & NS \\
\hline $\begin{array}{l}\text { Loh et al (2018) } \\
\text { [37] }\end{array}$ & $\begin{array}{l}\text { Most patients ( } \mathrm{n}=10,63 \%) \text { and caregivers } \\
(\mathrm{n}=8,73 \%) \text { enjoyed using the eHealth app } \\
\text { to connect with their care providers and } \\
\text { manage their health. Most patients or } \\
\text { caregivers found the health app easy to } \\
\text { use }\end{array}$ & $\begin{array}{l}\text { One patient }(6 \%) \text { suggested that } \\
\text { the app may be difficult for some- } \\
\text { one with less experience using } \\
\text { technology }\end{array}$ & $\begin{array}{l}25 \%(4 / 16) \text { of patients commented } \\
\text { that the app would be most useful } \\
\text { for patients living alone }\end{array}$ & NS \\
\hline $\begin{array}{l}\text { Nahm et al } \\
\text { (2019) [41] }\end{array}$ & NS & NS & $\begin{array}{l}\text { Patient portal training improved user } \\
\text { health decision-making, patient- } \\
\text { provider communication, and } \\
\text { eHealth literacy. At } 4 \text { months after } \\
\text { patient portal training, changes in } \\
\text { self-efficacy }(P=.02) \text { and patient } \\
\text { portal usage }(P=.03) \text { were signifi- } \\
\text { cant }\end{array}$ & NS \\
\hline $\begin{array}{l}\text { Portz et al } \\
\text { (2019) [38] }\end{array}$ & $\begin{array}{l}\text { Users suggested the patient portal was } \\
\text { useful for accessing health information } \\
\text { and communicating with their health care } \\
\text { providers }\end{array}$ & $\begin{array}{l}\text { Users were anxious that program } \\
\text { updates would cause the portal to } \\
\text { become unfamiliar or too difficult } \\
\text { to use }\end{array}$ & $\begin{array}{l}\text { Users believed the patient portal } \\
\text { saved them time and money }\end{array}$ & NS \\
\hline $\begin{array}{l}\text { Smallwood et al } \\
\text { (2017) [42] }\end{array}$ & $\begin{array}{l}\text { Participants were able to complete the } \\
\text { web-based decision aid with minimal as- } \\
\text { sistance. Subjects who used the decision } \\
\text { aid compared with those who did not use } \\
\text { it felt more prepared to make decisions } \\
\text { about their treatment }(P<.001)\end{array}$ & $\begin{array}{l}\text { Some patients }(n=5,17.2 \%) \text { incor- } \\
\text { rectly entered information into the } \\
\text { decision tool }\end{array}$ & NS & NS \\
\hline $\begin{array}{l}\text { Toscos et al } \\
(2016)[45]\end{array}$ & $\begin{array}{l}\text { The mean activation of participants was } \\
\text { of the highest possible level (level 4) } \\
\text { throughout the study }\end{array}$ & NS & $\begin{array}{l}\text { Patient activation was higher in } \\
\text { portal users, but not statistically } \\
\text { significant. Portal users showed } \\
\text { health improvements at } 12 \text { months } \\
\text { in } \mathrm{HbA}_{1 \mathrm{c}} \text { b } \mathrm{LDL}^{\mathrm{c}}, \mathrm{SBP}^{\mathrm{d}} \text {, and } \mathrm{DBP}^{\mathrm{e}} \text {, } \\
\text { but only } \mathrm{HbA}_{1 \mathrm{c}}(-0.19 ; P=.005) \text { was } \\
\text { statistically significant. BMI was } \\
\text { unchanged throughout the study }\end{array}$ & NS \\
\hline
\end{tabular}

${ }^{a}$ NS: not studied.

${ }^{\mathrm{b}} \mathrm{HbA}_{1 \mathrm{c}}$ : glycated hemoglobin A1c.

${ }^{\mathrm{c}}$ LDL: low-density lipoprotein.

${ }^{\mathrm{d}} \mathrm{SBP}$ : spontaneous bacterial peritonitis.

${ }^{\mathrm{e}}$ DBP: diastolic blood pressure.

Although participants were generally positive about the use of eHealth to receive screening or test results, several studies noted that older adults reported feeling anxious about using eHealth technology $[38,39,44]$. Participants-especially those with low health literacy-felt afraid to make mistakes because of their lack of technological experience. Many of these patients commented that computer use was not common in their working environment, which accounted for their lack of experience. 
These participants often avoided technology use altogether and preferred a family member accessing their patient portal on their behalf [44]. Participants in the study by Portz et al [38] noted specific anxiety about program updates to eHealth tools that made eHealth tools difficult to use after patients had learned and were comfortable with the tools. Difficulty in interpreting and applying laboratory results was also a concern among older eHealth users [39]. However, several studies noted that patients still enjoyed being able to view their laboratory results on the web $[38,39]$.

Despite computer anxiety being common among this population, many older adults, including those with low health literacy, were still interested in learning how to use a patient portal [44]. Patient portal training may be an important solution to low confidence that prevents many older adults from utilizing patient portals. Nahm et al [41] conducted an RCT and found that a theory-based patient portal e-learning program resulted in statistically significant improvements in patient portal self-efficacy, health decision-making, patient-provider communication, and eHealth literacy 3 weeks after portal training. Patient portal self-efficacy remained significantly higher in the intervention group at 4 months [41]. Participants from several studies recommended providing an instructional video or detailed written instructions to aid platform navigation $[40,43]$. Participants with both high and low health literacy felt that task-based training programs were a valuable but underutilized tool to increase confidence and knowledge on how to navigate eHealth tools [44].

\section{Objective 2: Designing eHealth Tools for Older Adults}

All 9 studies included in this review provided recommendations on how to develop eHealth tools that are intuitive, useful, and engaging for older adults. The specific recommendations can be divided into 3 basic categories: (1) user interface (how the participant interacts with the eHealth tool), (2) functionality (what the participant wants the eHealth tool to do), and (3) information included (what the participant wants the eHealth tool to say). A summary of the recommendations can be found in Table 3. 
Table 3. Older adult and investigator recommendations for eHealth tools.

\begin{tabular}{ll}
\hline Theme and study & Older adult recommendation \\
\hline User interface & \\
$\begin{array}{l}\text { Alpert et al (2016) } \\
\text { [39] }\end{array}$ & - $\quad \begin{array}{l}\text { Write information as bulleted lists } \\
\text { Dictionary to look up challenging terminology }\end{array}$ \\
Baier et al (2015) & - If the page requires scrolling to view all the content, add \\
[40] & a pop-up to remind the user to scroll down \\
& - $\begin{array}{l}\text { Allow users the option to increase font size } \\
\text { Results and health information should be easily printed } \\
\text { The web-based apps should be optimized for mobile de- } \\
\text { vices }\end{array}$
\end{tabular}

Investigator recommendation

- Create an interactive user interface

- Use images that represent the information being presented

- Use motivational voice, not passive voice

- Avoid writing in all caps

- Use serif fonts

- Use contrasting colors to enhance readability

- Provide prompts for functions

- Write at a sixth-grade reading level, limit technical language

- Include definitions for medical terms

- Directly label graphs

- Limit comparisons with 3-4 points

Jongstra et al (2017) - Use language that focuses on health rather than disease

[43] - Log-in passwords should not be complicated

- Include interactive features

- Health information should be easily printed

- Use large font size

- Use simple and consistent layout with large buttons

- Use images and distinct colors to facilitate page navigation

- Include audio option

Loh et al (2018) [37] N/A

- Ensure reliable internet access

- Provide stylus for touchscreen devices

- Provide a list of voice options if audio included

- Optimize the app for mobile phones and tablets

- Ensure screen brightness, font and color are easily readable

Portz et al (2019)

- Use larger font and contrasting colors

N/A

[38]

Smallwood et al N/A

(2017) [42]

- Automatic entry of patient's lab scores to decrease incorrect information

\section{Functionality}

Alpert et al (2016)

Baier et al (2015)

[40]

Irizarry et al (2017) [44] [43]
Jongstra et al (2017)
- Provide a way for patients to ask questions about navigat- ing the online platform
- Include an instructional video to aid in platform naviga- tion

formation received on the portal

- Seamless and intuitive password retrieval

- Add detailed instructions at the beginning of the eHealth tool to help users learn how to navigate the tool

- Include task-based training to help users understand how to navigate the different features of the patient portal Loh et al (2018) [37] - $\quad \begin{aligned} & \text { Participants found functions including appointments, } \\ & \text { medications, nutrition, and exercise reminders helpful }\end{aligned}$
- Ability for physician to confirm if their patient viewed or understood the information provided to them

N/A

- Integrate the patient portal with in-person clinical encounters

- Allow personnel to edit missing or inaccurate information in the patient portal

- Include games, goal setting, automated messages among other interactive features to motivate eHealth use

- If symptom reporting is included, ensure that feedback is provided on reported symptoms

- Provide digital activity tracker when exercise intervention is recommended

- Incorporate nonmedical functions such as social activities, jokes, games, etc

- Implement patient portal training for older adults 


\begin{tabular}{llll}
\hline Theme and study & Older adult recommendation & Investigator recommendation \\
\hline $\begin{array}{l}\text { Portz et al (2019) } \\
{[38]}\end{array}$ & $\bullet \begin{array}{l}\text { Participants were interested in using e-visits and chat } \\
\text { functions with providers }\end{array}$ & $\bullet \begin{array}{l}\text { Portal designers should consider including functions } \\
\text { that integrate eHealth with physical clinic visits }\end{array}$
\end{tabular}

\section{Information included}

Alpert et al (2016) [39]

- Include personalized, not generic health information

N/A

- Patients appreciated receiving laboratory results but sometimes had difficulty interpreting them

Jongstra et al (2017) - Provide practical and reliable health information [43]

Loh et al (2018) [37] N/A

N/A [45]

- Tailor interventions and activities to the individual

- Apply a user-centered design approach to tailor the portal to the specific population that it is designed for

${ }^{\mathrm{a} N} / \mathrm{A}$ : not applicable.

\section{User Interface}

A total of 7 studies made recommendations regarding how to design a user interface that is accommodating for older adults [37-40,42,43]. Most of the design recommendations suggested how to develop platforms that are easier to read and navigate. Recommendations included using a simple layout with large font, contrasting colors, and images that relate to the content [37-40]. Participants also wanted the technology to work seamlessly, with uncomplicated log-in, the ability to print information, and the ability to use the tool on smartphones and tablets $[37,40,43]$. Participants not only focused on the visuals and layout but also the tone, with recommendations for eHealth tools to use language that is motivating and positive and focuses on health rather than disease [39,43]. Finally, several studies recommended using an interface that is interactive to engage the user and encourage them to continue using the eHealth tool $[39,43]$.

\section{Functionality}

A total of 7 studies identified functions that participants found most useful to be included in an eHealth tool [37-41,43,44]. A common suggestion among older adults was to include detailed instructions within the eHealth tool $[20,40,43,44]$. Several suggestions were given as to how instructions should be included. Participants in the study by Baier et al [40] recommended detailed written instructions accessible within the eHealth tool. Participants in the study by Irizarry et al [44] suggested that task-based training was most helpful for learning how to navigate the tool. Alternatively, instructional videos and communication methods that allowed participants to ask questions about navigating the platform were recommended by participants in the study by Jongstra et al [43].

Both authors and participants of 3 studies commented that the eHealth tool should be integrated with the in-person clinical environment $[38,39,44]$. Participants commonly cited the ability to communicate with their physician through the eHealth tool as an enjoyable and useful feature [38,39]. Physicians generally felt that the patient portal empowered patients, but they wanted the ability to confirm if their patient viewed and understood the information provided to them via the eHealth tool [39]. Portz et al [38] suggested using face to face or phone time to encourage portal use in patients.

Finally, 2 studies recommended including fun, interactive features such as games, jokes, social activities, or automated motivational messages to promote tool use and make the tool more enjoyable for older adults [37,43].

\section{Information Included}

A total of 4 studies made recommendations regarding which information older adults found most useful to include in an eHealth tool $[37,39,43,45]$. Two studies found that personalized health information is more useful and engaging for older adults than generic health information [37,39]. Toscos et al [45] suggested that applying a user-centered design approach to the development of eHealth tools may promote the inclusion of information that is more tailored to older adults. Participants also wanted practical and reliable health information included in the eHealth tool [43].

\section{Discussion}

\section{Principal Findings}

The aims of this systematic review were two-fold. First, we were interested in understanding how receiving health screening in a web-based environment without the presence of a health care provider affects satisfaction, perceived harm, quality of life, and health care use by older adults. Second, we were interested in consolidating evidence-based recommendations on how to design eHealth tools that are useful and engaging for older adults. We found that older adults generally had positive experiences with receiving test results via eHealth tools, and numerous features have been suggested to enhance patients' web-based experiences. Although much literature is available on the impact of eHealth tools for younger patients, older adults represent a unique subgroup of patients whose needs differ greatly [46-48]. To the best of our knowledge, there are currently no systematic reviews on the effects of receiving health screening or results via eHealth tools either on older adults' health care satisfaction, perceived harms, quality of life, or health care use or on the optimal design for eHealth tools for older adults. It is important to understand the unique experiences 
of older adults because they are often less proficient with technology than younger patients are and may require different supports [49]. As a rapidly growing population of health care consumers, older adults are positioned to benefit greatly from the use of eHealth tools if these tools are designed in ways that are attractive to older adults.

From the 9 studies included in our review, several key themes emerged. Multiple studies noted that while older adults were generally optimistic about eHealth tools, lack of technology experience and fear of failure were barriers to use $[37,38,44]$. Both older adults and researchers recommended detailed instructions and comprehensive training to improve older adults' confidence in using eHealth tools $[40,41,43,44]$. Although it is encouraging that most older adults found receiving screening tests and results via eHealth to be useful, there is currently not enough research available to draw conclusions on the impact of receiving test results in a web-based environment without the presence of health care providers on older adult satisfaction, perceived harm, and quality of life. The possible harms of providing older adults with screening results via eHealth tools are anxiety caused by technology use, confusion among older adults who may be unable to interpret their results, and disparity caused by those who are less likely to benefit from eHealth tools because of low technology or health literacy. We were unable to find any information on the effect of eHealth screening tools on older adult health care utilization and hence cannot recognize any trends or draw any conclusion on health care use.

There were substantial recommendations from the studies included in this systematic review on how to design eHealth tools for older adults. A user interface that is accessible and intuitive to older adults is imperative for promoting tool uptake and use and was the most commonly made recommendation provided by older adults. Further recommendations included ensuring that the layout and text used in the tool is accessible to users with vision or hearing impairments and is logical to those with less technological experience. Furthermore, eHealth tools should be enjoyable for older adults to use. Designing a tool that includes interactive features, uses a positive tone, and ensures a seamless technological experience creates an environment that promotes eHealth tool uptake.

To promote eHealth use among older adults, the tools must provide functions and content that are useful for older adults. Participants emphasized the importance of integrating the eHealth tools with the physical clinic environment by facilitating communication with their physicians. Older adults suggested that personalized information, interventions, and activities were more useful and engaging than generic recommendations.

\section{How Does This Compare With the Literature?}

Although there are several systematic reviews that investigate the effect of eHealth tools on healthy aging outcomes such as physical activity, diet, and psychological well-being [50-52], we were unable to find a systematic review that investigated the effects of receiving screening results without the presence of health care providers in older adults. Furthermore, we were unable to find a systematic review that consolidated evidence-based recommendations for designing eHealth tools for older adults. Kampmeijer et al [53] completed a systematic review on the use of eHealth tools in health promotion and primary prevention for older adults. Similar to our findings, Kampmeijer et al [53] found that usability and accessibility were important facilitating factors in older adults' use of eHealth tools [53]. Buyl et al [52] completed a systematic review on the effect of eHealth interventions on healthy aging outcomes such as physical activity, psychological well-being, and overall health. Similar to our study, Buyl et al [52] were unable to draw conclusions on most health-related outcomes as they also found the quality of studies to vary considerably and the certainty of evidence to be low. However, Buyl et al [52] found that eHealth tool use improved older adults' physical activity. Strengthening digital competency was a critical component of encouraging eHealth tool use among older adults, which is similar to our finding that older adults desire training programs to feel confident in using eHealth tools. However, our study differs from those by Buyl et al [52] and Kampmeijer et al [53] because both studies investigated eHealth tools that encouraged physical activity, psychological well-being, and primary prevention strategies for older adults, whereas we investigated tools that provided screening results to older adults without health care providers present. Furthermore, Narasimha et al [54] completed a systematic review of the optimal design of telemedicine for older adults. Encouragingly, the authors found that older adults were generally positive about their experience with telehealth, although a lack of confidence with technology and physical impairments (for example, hearing difficulty) proved to be a challenge. These results are similar to our findings that although older adults are optimistic and willing to use eHealth tools, designing tools that accommodate common physical impairments and include training are important for user confidence and uptake. Our systematic review is different from Narasimha et al [54] because we investigated evidence-based recommendations for developing eHealth tools, not telemedicine.

\section{Limitations}

After removing duplicate and irrelevant papers, a small number of studies were used for our final analysis, which limits the generalizability of our findings. Although many titles and abstracts were found, we applied the RCT filter as we were interested in studies that examined the intervention ideally to a comparator group. However, few studies used an RCT design, and 4 studies used a qualitative design. By applying the RCT filter, it is possible that we may have missed additional qualitative studies. However, the gold standard for evaluating interventions is the RCT design, and these studies, including quasi-experimental studies, would have been identified in our search. Furthermore, most of the studies used convenience sampling to recruit participants, which introduces significant selection bias. In addition, the studies often had small sample sizes of less than 100 patients. These limitations further constrain the applicability of the results to larger and more diverse populations. Finally, many studies did not look at the sustainability of portal use, or the duration of follow-up was not reported. Therefore, it is unclear if any benefits that were identified are sustained over a significant period. 


\section{Implications}

Our findings suggest that although older adults are generally satisfied with receiving screening tests and results via eHealth tools, improper design, and lack of confidence with technology are common barriers to use in this population. Patients and caregivers should initially receive basic training on how to use eHealth tools to mitigate patient concerns (eg, about complex user interfaces) and minimize the impact of low computer literacy. To optimize the usability of eHealth tools, they should include customizable features (such as alerts, medication reminders, and appointment scheduling) as well as easy-to-read displays (eg, with large fonts and contrasting colors). In addition, eHealth tools should be integrated with physical clinic visits to facilitate communication between patients and their health care providers. By incorporating these features routinely into the design of patient portals, older adults will be more likely to embrace technology that can potentially improve their health. However, our review demonstrates that the literature on this topic remains sparse, and there is a need to further study the effects of eHealth tools on important patient-centered outcomes such as satisfaction, perceived harm, quality of life, and health care use. Older patients highly value the ability to remain at home, and avoiding emergency room visits and hospitalizations, making this an important outcome to consider in research involving older adults [8-10].

The findings from this systematic review will aid in the design of our CHAMP tool for older adults with cancer. Notably, one aim of this systematic review was to understand the impact of receiving test results in a web-based environment without the presence of health care providers on older adults. Although older adults generally appreciated receiving their results on the web, several studies noted that older adults desired the option to review their results with a health care professional. This supports our proposed CHAMP tool in which patients will use the tool to receive health care recommendations specific to their needs. Patients who are in high need of geriatric interventions will be identified and triaged to see a geriatrician. Those who are determined to have a low need for geriatric support will receive evidence-based recommendations determined by their unique health care needs and goals. These patients may also use the findings and recommendations of the CHAMP tool in discussions with their primary practitioner or oncologist. Hence, both low- and high-risk patients have the option to review and discuss the findings from the CHAMP eHealth tool with a health care professional.

The abundance of design recommendations made by older adults in the studies included in this systematic review will aid us in designing the CHAMP tool in a way that is most intuitive for older adults. Several design recommendations such as goal setting, live chat functions, and interactive games are more suited toward eHealth tools that are meant to be used longitudinally, whereas the CHAMP tool will be a one-time eHealth screening tool. However, these recommendations are still useful for researchers designing longitudinal eHealth tools for older adults.

\section{Recommendations for Future Research}

The development and use of eHealth tools among older adults are an understudied area with an opportunity for more learning, particularly given the growing uptake of eHealth tools by older adults [55]. Currently, there is not enough research available to draw conclusions about the impact of receiving test results on the web on outcomes such as satisfaction, perceived harms, quality of life, and health care use for older adults. Future studies should investigate these outcomes in controlled trials that examine the impact of receiving test results on the web without a health care provider present. Future studies should also use random sampling methods that allow for greater generalization of the results. Finally, we were unable to find any research on the long-term implications of eHealth tools on the health and well-being of older adults or on health care use. Future studies should incorporate long-term follow-up and include health care use as an outcome to understand the extent of the benefits of eHealth tools.

\section{Acknowledgments}

This study was funded by a grant from the Academic Health Sciences Centres Innovation Fund of the Ontario Ministry of Health and Long-Term Care. MP is supported by a Canada Research Chair in the Care of the Frail Older Adults.

\section{Conflicts of Interest}

None declared.

\section{Multimedia Appendix 1}

MEDLINE search.

[DOCX File, 16 KB-Multimedia Appendix 1]

\section{Multimedia Appendix 2}

Quality assessment of included studies assessed with the Mixed Methods Appraisal Tool.

[DOCX File, 15 KB-Multimedia Appendix 2]

\section{References}


1. Mohile SG, Dale W, Somerfield MR, Schonberg MA, Boyd CM, Burhenn PS, et al. Practical assessment and management of vulnerabilities in older patients receiving chemotherapy: ASCO guideline for geriatric oncology. J Clin Oncol 2018 Aug 01;36(22):2326-2347 [FREE Full text] [doi: 10.1200/JCO.2018.78.8687] [Medline: 29782209]

2. Wildiers H, Heeren P, Puts M, Topinkova E, Janssen-Heijnen ML, Extermann M, et al. International Society of Geriatric Oncology consensus on geriatric assessment in older patients with cancer. J Clin Oncol 2014 Aug 20;32(24):2595-2603 [FREE Full text] [doi: 10.1200/JCO.2013.54.8347] [Medline: 25071125]

3. Reuben DB, Fishman LK, McNabney M, Wolde-Tsadik G. Looking inside the black box of comprehensive geriatric assessment: a classification system for problems, recommendations, and implementation strategies. J Am Geriatr Soc 1996 Jul;44(7):835-838. [doi: 10.1111/j.1532-5415.1996.tb03744.x] [Medline: 8675935]

4. McCleary NJ, Wigler D, Berry D, Sato K, Abrams T, Chan J, et al. Feasibility of computer-based self-administered cancer-specific geriatric assessment in older patients with gastrointestinal malignancy. Oncologist 2013;18(1):64-72 [FREE Full text] [doi: 10.1634/theoncologist.2012-0241] [Medline: 23287880]

5. Hurria A, Akiba C, Kim J, Mitani D, Loscalzo M, Katheria V, et al. Reliability, validity, and feasibility of a computer-based geriatric assessment for older adults with cancer. J Oncol Pract 2016 Dec;12(12):e1025-e1034 [FREE Full text] [doi: 10.1200/JOP.2016.013136] [Medline: 27624950]

6. Shahrokni A, Tin A, Downey RJ, Strong V, Mahmoudzadeh S, Boparai MK, et al. Electronic rapid fitness assessment: a novel tool for preoperative evaluation of the geriatric oncology patient. J Natl Compr Canc Netw 2017 Feb;15(2):172-179 [FREE Full text] [doi: 10.6004/jnccn.2017.0018] [Medline: 28188187]

7. Sakaguchi-Tang DK, Bosold AL, Choi YK, Turner AM. Patient portal use and experience among older adults: systematic review. JMIR Med Inform 2017 Oct 16;5(4):e38 [FREE Full text] [doi: 10.2196/medinform.8092] [Medline: 29038093]

8. Akpan A, Roberts C, Bandeen-Roche K, Batty B, Bausewein C, Bell D, et al. Standard set of health outcome measures for older persons. BMC Geriatr 2018 Feb 02;18(1):36 [FREE Full text] [doi: 10.1186/s12877-017-0701-3] [Medline: 29394887]

9. Fleming MO, Haney TT. An imperative: patient-centered care for our aging population. Ochsner J 2013;13(2):190-193 [FREE Full text] [Medline: 23789003]

10. Mason NR, Sox HC, Whitlock EP. A patient-centered approach to comparative effectiveness research focused on older adults: lessons from the patient-centered outcomes research institute. J Am Geriatr Soc 2019 Jan;67(1):21-28 [FREE Full text] [doi: 10.1111/jgs.15655] [Medline: $\underline{30586155}$ ]

11. My HealtheVet. 2016 May 17. URL: https://www.myhealth.va.gov/mhv-portal-web/home [accessed 2021-01-27]

12. Ancker JS, Witteman HO, Hafeez B, Provencher T, Van de Graaf M, Wei E. The invisible work of personal health information management among people with multiple chronic conditions: qualitative interview study among patients and providers. J Med Internet Res 2015 Jun 04;17(6):e137 [FREE Full text] [doi: 10.2196/jmir.4381] [Medline: 26043709]

13. Widmer RJ, Collins NM, Collins CS, West CP, Lerman LO, Lerman A. Digital health interventions for the prevention of cardiovascular disease: a systematic review and meta-analysis. Mayo Clin Proc 2015 Apr;90(4):469-480 [FREE Full text] [doi: 10.1016/j.mayocp.2014.12.026] [Medline: 25841251]

14. El-Gayar O, Timsina P, Nawar N, Eid W. A systematic review of IT for diabetes self-management: are we there yet? Int $\mathbf{J}$ Med Inform 2013 Aug;82(8):637-652. [doi: 10.1016/j.ijmedinf.2013.05.006] [Medline: 23792137]

15. Zettel-Watson L, Tsukerman D. Adoption of online health management tools among healthy older adults: an exploratory study. Health Informatics J 2016 Jun;22(2):171-183 [FREE Full text] [doi: 10.1177/1460458214544047] [Medline: 25149210]

16. Ferreira A, Correia A, Silva A, Corte A, Pinto A, Saavedra A, et al. Why facilitate patient access to medical records. Stud Health Technol Inform 2007;127:77-90. [Medline: 17901601]

17. Latulipe C, Gatto A, Nguyen HT, Miller DP, Quandt SA, Bertoni AG, et al. Design considerations for patient portal adoption by low-income, older adults. Proc SIGCHI Conf Hum Factor Comput Syst 2015 Apr;2015:3859-3868 [FREE Full text] [doi: 10.1145/2702123.2702392] [Medline: 27077140]

18. Lober WB, Zierler B, Herbaugh A, Shinstrom SE, Stolyar A, Kim EH, et al. Barriers to the use of a personal health record by an elderly population. AMIA Annu Symp Proc 2006:514-518 [FREE Full text] [Medline: 17238394]

19. Turner AM, Osterhage K, Hartzler A, Joe J, Lin L, Kanagat N, et al. Use of patient portals for personal health information management: the older adult perspective. AMIA Annu Symp Proc 2015;2015:1234-1241 [FREE Full text] [Medline: $\underline{26958263]}$

20. Nahm ES, Sagherian K, Zhu S. Use of patient portals in older adults: a comparison of three samples. Stud Health Technol Inform 2016;225:354-358. [Medline: 27332221]

21. Smith SG, O'Conor R, Aitken W, Curtis LM, Wolf MS, Goel MS. Disparities in registration and use of an online patient portal among older adults: findings from the LitCog cohort. J Am Med Inform Assoc 2015 Jul;22(4):888-895 [FREE Full text] [doi: 10.1093/jamia/ocv025] [Medline: 25914099]

22. Montelius E, Astrand B, Hovstadius B, Petersson G. Individuals appreciate having their medication record on the web: a survey of attitudes to a national pharmacy register. J Med Internet Res 2008 Nov 11;10(4):e35 [FREE Full text] [doi: 10.2196/jmir.1022] [Medline: 19000978]

23. Aalbers T, Baars M, Rikkert MO. Designing a personal health application for older adults to manage medications. In: Proceedings of the 1st ACM International Health Informatics Symposium. 2010 Presented at: ACM International Health Informatics Symposium; November, 2010; Arlington Virginia USA. [doi: 10.1145/1882992.1883124] 
24. Goldzweig CL, Orshansky G, Paige NM, Towfigh AA, Haggstrom DA, Miake-Lye I, et al. Electronic patient portals: evidence on health outcomes, satisfaction, efficiency, and attitudes: a systematic review. Ann Intern Med 2013 Nov 19;159(10):677-687. [doi: 10.7326/0003-4819-159-10-201311190-00006] [Medline: 24247673]

25. Laine C, Davidoff F. Patient-centered medicine. A professional evolution. J Am Med Assoc 1996 Jan 10;275(2):152-156. [Medline: 8531314]

26. Schulkes KJ, Nguyen C, van den Bos F, Hamaker ME, van Elden LJ. Patient-centered outcome measures in lung cancer trials. Lung 2016 Aug;194(4):647-652. [doi: 10.1007/s00408-016-9903-2] [Medline: 27287676]

27. Cochrane Handbook for Systematic Reviews of Interventions. URL: https://training.cochrane.org/ cochrane-handbook-systematic-reviews-interventions [accessed 2021-01-27]

28. Moher D, Liberati A, Tetzlaff J, Altman DG, PRISMA Group. Preferred reporting items for systematic reviews and meta-analyses: the PRISMA statement. PLoS Med 2009 Jul 21;6(7):e1000097 [FREE Full text] [doi:

10.1371/journal.pmed.1000097] [Medline: 19621072]

29. The Cochrane Collaboration. Technical Supplement to Chapter 4: Searching for and selecting studies. In: Cochrane Handbook for Systematic Reviews of Interventions Version 6. United Kingdom: Cochrane Training; 2019.

30. Eady AM, Wilczynski NL, Haynes RB. PsycINFO search strategies identified methodologically sound therapy studies and review articles for use by clinicians and researchers. J Clin Epidemiol 2008 Jan;61(1):34-40 [FREE Full text] [doi: 10.1016/j.jclinepi.2006.09.016] [Medline: 18083460]

31. Glanville J, Dooley G, Wisniewski S, Foxlee R, Noel-Storr A. Development of a search filter to identify reports of controlled clinical trials within CINAHL Plus. Health Info Libr J 2019 Mar;36(1):73-90. [doi: 10.1111/hir.12251] [Medline: 30737884]

32. Wong SS, Wilczynski NL, Haynes RB. Developing optimal search strategies for detecting clinically sound treatment studies in EMBASE. J Med Libr Assoc 2006 Jan;94(1):41-47 [FREE Full text] [Medline: 16404468]

33. Better systematic review management. Covidence. URL: https://www.covidence.org/ [accessed 2021-01-27]

34. Hong QN, Gonzalez-Reyes A, Pluye P. Improving the usefulness of a tool for appraising the quality of qualitative, quantitative and mixed methods studies, the Mixed Methods Appraisal Tool (MMAT). J Eval Clin Pract 2018 Jun;24(3):459-467. [doi: 10.1111/jep.12884] [Medline: 29464873]

35. Hong QN, Pluye P, Fàbregues S, Bartlett G, Boardman F, Cargo M, et al. Improving the content validity of the mixed methods appraisal tool: a modified e-Delphi study. J Clin Epidemiol 2019 Jul;111:49-59.e1 [FREE Full text] [doi: 10.1016/j.jclinepi.2019.03.008] [Medline: 30905698]

36. Pace R, Pluye P, Bartlett G, Macaulay AC, Salsberg J, Jagosh J, et al. Testing the reliability and efficiency of the pilot Mixed Methods Appraisal Tool (MMAT) for systematic mixed studies review. Int J Nurs Stud 2012 Jan;49(1):47-53. [doi: 10.1016/j.ijnurstu.2011.07.002] [Medline: 21835406]

37. Loh KP, Ramsdale E, Culakova E, Mendler JH, Liesveld JL, O'Dwyer KM, et al. Novel mHealth app to deliver geriatric assessment-driven interventions for older adults with cancer: pilot feasibility and usability study. JMIR Cancer 2018 Oct 29;4(2):e10296 [FREE Full text] [doi: 10.2196/10296] [Medline: 30373733]

38. Portz JD, Bayliss EA, Bull S, Boxer RS, Bekelman DB, Gleason K, et al. Using the technology acceptance model to explore user experience, intent to use, and use behavior of a patient portal among older adults with multiple chronic conditions: descriptive qualitative study. J Med Internet Res 2019 Apr 08;21(4):e11604 [FREE Full text] [doi: 10.2196/11604] [Medline: $\underline{30958272]}$

39. Alpert JM, Krist AH, Aycock RA, Kreps GL. Applying multiple methods to comprehensively evaluate a patient portal's effectiveness to convey information to patients. J Med Internet Res 2016 May 17;18(5):e112 [FREE Full text] [doi: 10.2196/jmir.5451] [Medline: 27188953]

40. Baier RR, Cooper E, Wysocki A, Gravenstein S, Clark M. Using qualitative methods to create a home health web application user interface for patients with low computer proficiency. EGEMS (Wash DC) 2015;3(2):1166 [FREE Full text] [doi: 10.13063/2327-9214.1166] [Medline: 26290893]

41. Nahm ES, Zhu S, Bellantoni M, Keldsen L, Russomanno V, Rietschel M, et al. The effects of a theory-based patient portal e-learning program for older adults with chronic illnesses. Telemed J E Health 2019 Oct;25(10):940-951 [FREE Full text] [doi: 10.1089/tmj.2018.0184] [Medline: 30431393]

42. Smallwood AJ, Schapira MM, Fedders M, Neuner JM. A pilot randomized controlled trial of a decision aid with tailored fracture risk tool delivered via a patient portal. Osteoporos Int 2017 Feb;28(2):567-576. [doi: 10.1007/s00198-016-3767-4] [Medline: 27647529]

43. Jongstra S, Beishuizen C, Andrieu S, Barbera M, van Dorp M, van de Groep B, et al. Development and validation of an interactive internet platform for older people: the healthy ageing through internet counselling in the elderly study. Telemed J E Health 2017 Feb;23(2):96-104. [doi: 10.1089/tmj.2016.0066] [Medline: 27463120]

44. Irizarry T, Shoemake J, Nilsen ML, Czaja S, Beach S, DeVito Dabbs A. Patient portals as a tool for health care engagement: a mixed-method study of older adults with varying levels of health literacy and prior patient portal use. J Med Internet Res 2017 Mar 30;19(3):e99 [FREE Full text] [doi: 10.2196/jmir.7099] [Medline: 28360022]

45. Toscos T, Daley C, Heral L, Doshi R, Chen YC, Eckert GJ, et al. Impact of electronic personal health record use on engagement and intermediate health outcomes among cardiac patients: a quasi-experimental study. J Am Med Inform Assoc 2016 Jan;23(1):119-128. [doi: 10.1093/jamia/ocv164] [Medline: 26912538] 
46. Whitehead L, Seaton P. The effectiveness of self-management mobile phone and tablet apps in long-term condition management: a systematic review. J Med Internet Res 2016 May 16;18(5):e97 [FREE Full text] [doi: 10.2196/jmir.4883] [Medline: 27185295]

47. Ross J, Stevenson F, Lau R, Murray E. Factors that influence the implementation of e-health: a systematic review of systematic reviews (an update). Implement Sci 2016 Oct 26;11(1):146 [FREE Full text] [doi: 10.1186/s13012-016-0510-7] [Medline: 27782832]

48. de la Torre-Díez I, López-Coronado M, Vaca C, Aguado JS, de Castro C. Cost-utility and cost-effectiveness studies of telemedicine, electronic, and mobile health systems in the literature: a systematic review. Telemed J E Health 2015 Feb;21(2):81-85 [FREE Full text] [doi: 10.1089/tmj.2014.0053] [Medline: 25474190]

49. Levine DM, Lipsitz SR, Linder JA. Trends in seniors' use of digital health technology in the United States, 2011-2014. J Am Med Assoc 2016 Aug 02;316(5):538-540. [doi: 10.1001/jama.2016.9124] [Medline: 27483069]

50. Aalbers T, Baars MA, Rikkert MG. Characteristics of effective internet-mediated interventions to change lifestyle in people aged 50 and older: a systematic review. Ageing Res Rev 2011 Sep;10(4):487-497. [doi: 10.1016/j.arr.2011.05.001] [Medline: 21628005]

51. Robbins TD, Lim Choi Keung SN, Arvanitis TN. E-health for active ageing; A systematic review. Maturitas 2018 Aug;114:34-40. [doi: 10.1016/j.maturitas.2018.05.008] [Medline: 29907244]

52. Buyl R, Beogo I, Fobelets M, Deletroz C, Van Landuyt P, Dequanter S, et al. e-Health interventions for healthy aging: a systematic review. Syst Rev 2020 Jun 03;9(1):128 [FREE Full text] [doi: 10.1186/s13643-020-01385-8] [Medline: 32493515]

53. Kampmeijer R, Pavlova M, Tambor M, Golinowska S, Groot W. The use of e-health and m-health tools in health promotion and primary prevention among older adults: a systematic literature review. BMC Health Serv Res 2016 Sep 05;16 Suppl 5:290 [FREE Full text] [doi: 10.1186/s12913-016-1522-3] [Medline: 27608677]

54. Narasimha S, Madathil KC, Agnisarman S, Rogers H, Welch B, Ashok A, et al. Designing telemedicine systems for geriatric patients: a review of the usability studies. Telemed J E Health 2017 Jun;23(6):459-472. [doi: 10.1089/tmj.2016.0178] [Medline: 27875667]

55. Tech Adoption Climbs Among Older Adults. Pew Research Center. URL: https://www.pewresearch.org/internet/2017/05/ 17/tech-adoption-climbs-among-older-adults/ [accessed 2021-01-27]

\author{
Abbreviations \\ CHAMP: Comprehensive Health Assessment for My Plan \\ mHealth: mobile health \\ MMAT: Mixed Methods Appraisal Tool \\ PRISMA: Preferred Reporting Items for Systematic Reviews and Meta-analyses \\ RCT: randomized controlled trial
}

Edited by J Wang; submitted 03.09.20; peer-reviewed by T Risling, A Kapoor; comments to author 24.11.20; revised version received
10.12.20; accepted 06.01.21; published 09.02.21
Please cite as:
McLean B, Hossain N, Donison V, Gray M, Durbano S, Haase K, Alibhai SMH, Puts M
Providing Medical Information to Older Adults in a Web-Based Environment: Systematic Review
JMIR Aging 2021;4(1):e24092
URL: $\underline{\text { https://aging.jmir.org/2021/1/e24092 }}$
doi: $10.2196 / 24092$
PMID: $\underline{3350228}$

CBianca McLean, Nazia Hossain, Valentina Donison, Mikaela Gray, Sara Durbano, Kristen Haase, Shabbir Muhammad Husayn Alibhai, Martine Puts. Originally published in JMIR Aging (http://aging.jmir.org), 09.02.2021. This is an open-access article distributed under the terms of the Creative Commons Attribution License (https://creativecommons.org/licenses/by/4.0/), which permits unrestricted use, distribution, and reproduction in any medium, provided the original work, first published in JMIR Aging, is properly cited. The complete bibliographic information, a link to the original publication on http://aging.jmir.org, as well as this copyright and license information must be included. 